\title{
Territorialidade Narrativa: Tessituras jornalísticas da crise migratória
}

\author{
Fábio Ferreira Agra
}

\section{Resumo}

Este trabalho tem por objetivo fazer uma reflexão a respeito dos textos jornalísticos sobre a chamada "crise migratória" ou "crise dos refugiados" dentro de uma perspectiva que denominamos de territorialidade narrativa, ancorada nos estudos de Rogério Haesbaert (2004, 2009) e Fernando Resende $(2019,2020)$. Analisamos como a narrativa sobre espaços de fronteira e controle, ao que circunscreve a esta crise, é atravessada por uma visão de mundo que nos lega um entendimento dos acontecimentos sempre a partir dos mesmos referenciais e que se expande para outros territórios. Para esse trabalho, foram analisados textos do jornal Folha de São Paulo publicados em 2015 que diziam respeito à migração forçada diante de fronteiras e outros espaços de controle.

Palavras-chave: Migração. Narrativa. Territorialidade.

\section{Narrative Territoriality: Journalistic Interweaving of the migrant crisis}

\section{Abstract}

This paper aims to discuss the journalistic narratives about a so-called "migrant crisis" or "refugees crisis" within a perspective that we nominated "narrative territoriality, anchored in the studies of Rogério Haesbaert $(2004,2009)$ and Fernando Resende $(2019,2020)$. It is analyzed how the narrative about borders and spaces of control, which this crisis is also circumscribed, is crossed by a point of view that legate us an understanding of the historical events always from the same references and which it expands to other territories. For this paper it was analyzed some news from Folha de São Paulo newspaper that refer to the control of forced migration on borders and other spaces of control published in 2015.

Keywords: Migration. Narrative. Territoriality.

\footnotetext{
1 Fábio Ferreira Agra é doutorando em Comunicação pela Universidade Federal Fluminense (UFF); Mestre em Letras: Cultura, Educação e Linguagens (Universidade Estadual do Sudoeste da Bahia UESB) e graduado em Comunicação Social/Jornalismo (UESB). Membro do Travessia - Centro de Estudos e Pesquisas do Sul Global, e do LAN - Laboratório de Experimentação e Pesquisa de Narrativas da Mídia. Tem realizado pesquisas sobre jornalismo, narrativas, fronteiras, migração e refúgio. E-mail: ff-agra@hotmail.com. Este artigo foi financiado pela CAPES (Coordenação de Aperfeiçoamento de Pessoal de Nível Superior) e é fruto de um seminário apresentado no XII Encontro dos Programas de Pós-Graduação em Comunicação de Minas Gerais (ECOMIG 2019).
} 


\section{Introdução}

Nesta segunda década do século 21, a migração forçada e o refúgio ganharam contornos mais visíveis ao se multiplicarem às margens das fronteiras, especialmente das fronteiras externas da Europa. Em termos estatísticos, em apenas oito anos, o número de deslocamentos forçados no mundo saltou de 45,2 milhões de pessoas em 2012 para 70,8 milhões em 2018. Nesse mesmo período, a quantidade de refugiados no mundo passou de 15,4 milhões (2012) para 25,9 milhões (2018) (UNCHR, 2013, 2019).2

A Europa, ao final de $2015^{3}$, chegava a cerca de 4,3 milhões de pessoas refugiadas ou em situação de refúgio, 1,3 milhão a mais do que havia no início daquele ano. No entanto, apenas a Turquia, contabilizada pela UNCHR como parte do continente europeu, abrigava 2,5 milhões desse total. Em comparação, a África subsaariana continha em 2015 4,4 milhões de refugiados (UNCHR, 2016). A guerra na Síria, conflitos no Iraque e Afeganistão produziram a maioria dos refugiados com destino à Europa, especialmente para a Turquia, enquanto a Somália, Sudão, Sudão do Sul, República Democrática do Congo e República Centro-Africana eram responsáveis por cerca de $80 \%$ dos refugiados que se deslocavam pela região subsaariana (UNCHR, 2016). Mas, menos para servir de estatísticas, esses números nos dizem que o problema do deslocamento forçado e a necessidade de refúgio são tensões para além das fronteiras da Europa, continente que deu visibilidade para uma crise que já estava presente em outros territórios.

Nesse sentido, propomos que há um espraiamento sobre o entendimento desta crise a partir dos mesmos referenciais, que são os países europeus. A reflexão então se dá dentro de uma perspectiva que denominamos de territorialidade narrativa, ancorada nos estudos sobre territorialidade a partir de Rogério Haesbaert $(2004,2009)$ e de territorialidade narrativa em Fernando Resende (2019, 2020). Pontuamos nesse trabalho

2 Esse é o maior índice de deslocamento forçado já registrado pela Agência da Organização das Nações Unidas para Refugiados (ACNUR, ou UNCHR em inglês) em sua história. UNCHR foi criado em 1950 e iniciou suas atividades em 1951 para reassentar refugiados europeus após a Segunda Guerra Mundial. A partir de 1967, a Agência universaliza seus trabalhos e passa a atuar na proteção de refugiados em todo o mundo. Desde 2004, o UNCHR publica a cada ano no mês de junho um relatório global sobre deslocamentos forçados e de refugiados (Global Trends Report) referente ao ano anterior. Os dados sobre o número de deslocamentos forçados publicados em junho de 2019 indicaram que no ano de 2018 havia 70,8 milhões de pessoas nessa situação, sendo 25,9 milhões de refugiados. Disponível em: https://www.acnur.org/portugues/.

3 A quantidade de pessoas deslocadas de maneira forçada em 2015 chegava a 65,3 milhões, com 21,3 milhões de refugiados e 3,2 milhões de solicitantes de asilo (UHCHR, 2016). 

Desenvolvemos assim uma ideia de territorialidade narrativa dentro do jornalismo ao considerá-lo também como um possível mecanismo de manutenção e/ou atualização de determinadas visões de mundo e, consequentemente, de poder. ${ }^{4}$

Para a análise, foi feito um recorte em relação aos textos publicados pelo jornal Folha de São Paulo em 2015, ano que se intensifica os debates na imprensa europeia (GEORGIOU; ZABOROWSKI, 2017) sobre o tema do refúgio e que há um número maior de publicações pela Folha de São Paulo com o significante "refugiados"5 (Tabela 1). Com um aumento da cobertura do jornal Folha de São Paulo sobre o tema da migração forçada e do refúgio nos últimos anos, decidiu-se por um recorte do corpus em que se analisa apenas os textos que foram produzidos e publicados por jornalistas brasileiros na editoria Mundo do jornal, deixando fora do corpus de análise os textos republicados de outros jornais ou de agências de notícias, textos que apenas faziam menção aos refugiados dentro de outras pautas, entrevistas ou artigos de opinião.

Desta forma, foram 68 publicações de jornalistas brasileiros que diziam respeito aos deslocamentos forçados ou situação de refúgio. Desse total, separamos sete títulos sobre a Europa que conotassem tentativas de atravessamento de fronteiras por pessoas que buscavam refúgio ou que conotassem algum tipo de controle sobre elas. A análise foi feita a partir de uma ideia em que tentamos demonstrar como a territorialidade narrativa atravessa o jornalismo no momento de representar os acontecimentos relacionados ao refúgio. Foram escolhidos apenas os textos relativos à Europa, considerando que foi o território que mais atraiu a atenção da Folha de São Paulo sobre o tema, como veremos mais para frente. A partir dos sete títulos, analisamos duas matérias.

Tabela 1 - Quantidade de textos com o significante "refugiados" na Folha de São Paulo por ano entre 2010 e 2018 em sua editoria Mundo

\footnotetext{
4 Este trabalho busca discutir a territorialidade narrativa na imprensa por um de seus recortes que está assentado na ideia de uma territorialidade que expande visões hegemônicas através da narrativa. Este é apenas um dos caminhos para se pensar este problema a partir de Haesbaert (2004, 2009). Contudo, entendemos que a territorialidade narrativa também propicia outras ordens não hegemônicas, outros poderes e outras apropriações de território a partir do que é comum. Nesta perspectiva, a territorialidade narrativa é desenvolvida por Resende $(2019,2020)$.

5 A Folha de São Paulo nomeou os deslocamentos forçados entre 2015 e 2016 como "crise dos refugiados" em matérias publicadas na editoria Mundo.
} 


\begin{tabular}{|c|c|c|c|c|c|c|c|c|c|}
\hline Editoria Mundo & 2010 & 2011 & 2012 & 2013 & 2014 & $\mathbf{2 0 1 5}$ & 2016 & 2017 & 2018 \\
\hline Termo Refugiados & 351 & 443 & 355 & 306 & 306 & $\mathbf{5 2 6}$ & 517 & 408 & 476 \\
\hline
\end{tabular}

\section{A narrativa como uma malha em expansão}

Há dois vetores que nos ajudam a pensar a migração forçada a partir da narrativa dos meios de comunicação, em especial do jornalismo: um que concentra o debate na Europa, separando o que está dentro e fora de suas fronteiras, e se expande a partir dali, e um outro que, como efeito do primeiro, contribui para manter apagados outros territórios e sujeitos que migram em outras direções em condições de vulnerabilidade. Pensando com Zamin (2013), o jornalismo estabelece um mapa, cartografa os espaços e dá significados a eles a partir de uma desordem. Em relação à migração forçada, neste mapa há praticamente um traçado entre Europa e Síria quando analisamos a Folha de São Paulo. Há um recorte territorial que narra principalmente o que acontece nesta rota Europa/Oriente Médio quando nos deparamos com a migração forçada, a despeito de outros territórios concentrarem o mesmo problema.

Desta forma, ao considerarmos, por exemplo, que a chamada "crise dos refugiados" em 2015 ganhou realmente um status de crise quando estes sujeitos obrigados a fugir da guerra, como a da Síria, e de outras situações de vulnerabilidade se direcionam à Europa, ignora-se em certa medida os conflitos e migrações forçadas que se estabeleceram anterior e concomitantemente dentro de outros territórios, quando também são vivenciadas mortes e outras situações de risco. Segundo a UNCHR (2016), mais de $80 \%$ das pessoas em condições de refúgio procuram abrigo em países em desenvolvimento e próximo das fronteiras onde se dão algum tipo de conflito. No entanto, a visibilidade da migração forçada parece estar condicionada à qual direção estes sujeitos tomam, pois há um apagamento quando estes deslocamentos não estão diretamente conectados à Europa.

Pensamos assim na narrativa da grande imprensa brasileira, em que o país é em certa medida, a partir de suas raízes culturais, tão próximo da Europa quanto da África. Contudo, sua narrativa jornalística está mais propensa a ser parte de uma comunidade imaginada (ANDERSON, 2008) europeia a africana, o que resvala prontamente no debate e na circulação da notícia acerca da migração forçada e do refúgio. A imprensa, pensando com Anderson (2008), e nos estendemos às outras mídias, é um importante conector entre sujeitos e outros territórios e que justamente através de uma narrativa comum os 
fazem se sentir pertencentes à mesma cultura e se sentir próximos, mesmo além fronteiras.

Nesse sentido, essa reflexão nos joga uma luz, em um primeiro momento, sobre o interesse em se publicar mais sobre o que acontece na Europa do que em outros territórios. Dos 68 textos publicados por jornalistas brasileiros na Folha de São Paulo em 2015 sobre o tema, apenas um mencionava os deslocamentos forçados dentro do continente africano a partir da crise política no Burundi; ${ }^{2} 29$ publicações eram sobre a situação na Europa; 16 sobre o Oriente Médio, incluindo a fronteira entre Síria e Turquia; 11 textos sobre o tema a partir do Brasil; dois textos sobre a situação na Ásia, como em Myanmar, e dois textos sobre o tema do refúgio em geral.

Essa cartografia das publicações nos revela que, ao menos a Folha de São Paulo a partir de publicações dos jornalistas brasileiros, deu relevância ao que acontecia na Europa. É a partir dali que o debate se estabelece, embora mesmo que naquele ano a Europa não fosse o principal destino das pessoas que são obrigadas a se deslocar.

Dominique Wolton (2004) dizia que o jornalismo, que ele denomina de ocidental, era uma instância que se fechava em um círculo ao ter as mesmas instituições, figuras políticas, científicas e culturais para falar sobre o que acontecia no mundo. Como resultado, anulava outras perspectivas dos acontecimentos e produzia efeitos negativos que se retroalimentavam:

O pequeno círculo midiático ilumina com sua luz o pequeno círculo daqueles que ele considera como os mais competentes para se expressar. Os dois meios têm assim a ilusão de crer que só eles são representativos da realidade. Isso tem três efeitos negativos. O primeiro é selecionar mais do que abrir. O segundo é conceder uma legitimidade grande demais àqueles que fazem parte desse primeiro círculo. $O$ terceiro é instaurar um sistema em que os selecionadores e os selecionados se autoprotegem (WOLTON, 2004, p. 273-274).

Tais características midiáticas e suas narrativas se aproximam, no nosso entender, do que Haesbaert $(2004,2009)$ e Robert Sack (1983) vão pensar em termos de territorialidade. Para os autores, a territorialidade se configura como meio e/ou estratégia em que um agente expande influência, afeto e controle sobre pessoas, objetos e relações, sobre territórios físicos ou simbólicos, não se restringindo à sua demarcação em um único

6 Disponível em: https://www1.folha.uol.com.br/mundo/2015/05/1632834-burundi-vive-caos-apospresidente-anunciar-disputa-do-3-mandato.shtml. 
sentido material, geográfico ou dentro de uma fronteira estabelecida. Assim, para Haesbaert e Sack7, a territorialidade se dá através da ação humana que a configura sob uma dominação intencional e relacional.

As práticas produzidas por determinado agente e que se ocupa simultaneamente de outros territórios são estratégias de territorialidade, como o jornalismo faz ao ultrapassar as fronteiras geográficas e reverberar suas narrativas e representações, podendo estas serem ou não usadas para reiterar aspectos das práticas sociais e das relações de poder por meios simbólicos, onde determinados atores ganham relevo, dominam a produção de sentido político-cultural em relação a outros atores que têm menos força em uma relação de poder, como apontava Wolton sobre o jornalismo ocidental.

Desta forma, citando Sack (1986, p. 219) , Haesbaert (2004) afirma que "a territorialidade, como um componente do poder, não é apenas um meio para criar e manter a ordem, mas é uma estratégia para criar e manter grande parte do contexto geográfico através do qual nós experimentamos o mundo e o dotamos de significado". Zamin (2013, p. 106) diz que "os espaços, do mundo ou do próprio sistema, percorridos pelo Jornalismo não têm valor por si mesmos; eles significam por aquilo que acrescentam às narrativas dos acontecimentos." Em outras palavras, o contexto geográfico que experimentamos através das narrativas jornalísticas acerca da migração forçada em 2015 nos aponta também uma produção de sentido que resvala em uma maneira de se olhar o mundo sob uma perspectiva ainda europeia, pois é a partir daquele território que passamos a dar significado aos deslocamentos forçados.

Com isso, queremos dizer que não é possível descolar a territorialidade do seu campo simbólico, assim como não podemos dissociar territorialidade de narrativa, pois, a nosso ver, a territorialidade só é possível se for antecedida por uma construção narrativa em que seus efeitos produzem o desejo de territorialização, que pode ser concreta ou imagética/simbólica. Assim, podemos pensar que a territorialidade é como uma malha abstrata à qual se alastram ações simbólicas e culturais, de poder econômico e político e de controle para mais de um território concreto ou imagético. Para Haesbaert, ao

7 Definição de territorialidade em Sack (1983, p. 56): "The attempt by an individual or group (x) to influence, affect, or control objects, people and relationship (y) by delimiting and asserting control of a geographic area. This area is the territory".

8 SACK, R. 1986. Human Territoriality: its theory and history. Cambridge: Cambridge University Press. 

prescindível:

Embora todo território tenha uma territorialidade (tanto no sentido abstrato de 'qualidade ou condição de ser território' quanto no de sua dimensão real-simbólica), nem toda territorialidade - ou, se quisermos, também, aqui, espacialidade - possui um território (no sentido de sua efetiva realização material) (HAESBAERT, 2009, p. 106).

Essa expansão simbólica envolve se sentir afetado às práticas culturais e sociais alheias e pode ser pensada com o que Fernando Resende (2019, p. 7) denomina propriamente de territorialidade narrativa, que é o modo que uma relação é construída dentro e a partir de um sistema geopolítico, em que não se define ou se limita a uma geografia física. Aqui pontuamos, que nesse sentido, busca-se entender determinados gestos, ações e histórias em diferentes lugares que dialogam entre si através de algum prisma comum, como a herança das colonizações que aproxima os países do sul global, por exemplo, e a luta contra os resquícios de dominação política, econômica e cultural mantidos pelos países outrora colonizadores.

Resende (2020) afirma que as experiências comuns entre os sujeitos do sul global também produzem essa territorialidade através da narrativa que se inscreve nos corpos e em suas imagens onde:

fundamental para o processo de compreensão da construção social e cultural do território, esta territorialidade, construída através de narrativas (...) não é apenas a afirmação do território em si mesmo (...) mas a evocação da experiência em ser parte disso. Em outras palavras, a imagem em si mesmo produz territorialidade - uma experiência coletiva e compartilhada (RESENDE, 2020, p. 92). ${ }^{9}$

Nessa mesma perspectiva, Resende (2020) cita Zambrano $(2001)^{10}$ que diz que a territorialidade é um fenômeno similar ao da comunidade imaginada, que é capaz de gerar identificação entre percepções distintas. Em relação à migração forçada, as imagens dos sujeitos que estão nos botes em direção à Europa nos revelam também essa territorialidade. Os corpos que estão ali compartilham as mesmas experiências não

9 Tradução do autor. Ver RESENDE, Fernando. Geographies of the South: unfolding experiences and narratives territorialities, 2020, p. 92.

10 Ver ZAMBRANO, Carlos. Territorios Plurales: Cambio sociopolitico y gobernabilidad cultural. In: Boletin goiano de geografia. Vol. 21, $\mathrm{n}^{\circ} 1$ (Janeiro de 2001). 
somente do presente como refugiados, mas também de ex-colonizados e de vítimas da xenofobia.

Por outro lado, temos os meios de comunicação que catalisam para si não somente os acontecimentos que se arvoram, mas produzem também essas territorialidades, espacialidades, dominam e expandem as narrativas. Nesse sentido, Durval Muniz de Albuquerque Jr. (1999, p. 23) diz que é necessário "rompermos com as transparências dos espaços e das linguagens, pensarmos as espacialidades como acúmulo de camadas discursivas e de práticas sociais, trabalharmos nessa região em que linguagem (discurso) e espaço (objeto histórico) se encontram".

Para Motta (2013, p. 23) uma análise da comunicação narrativa pode servir como "instrumento interpretativo, uma técnica hermenêutica que revele processos de representação e de constituição da realidade historicamente situada, onde há confrontos com outras representações possíveis". Em um texto jornalístico, o processo hermenêutico nos joga luz e ajuda a pensar como a leitura de um acontecimento é refratada pelas intenções e decodificações de quem cria os significados, de quem constrói a realidade. Nesse sentido Charaudeau (2012, p. 16) enfatiza que essa realidade "trata-se da maneira pela qual os indivíduos regulam as trocas sociais, constroem as representações dos valores que subjazem a suas práticas, criando e manipulando signos e, por conseguinte, produzindo sentido".

Assim, em sua obra "Tempo e Narrativa", Paul Ricoeur (1994) nos aponta caminhos para entender a trama da narrativa, que se desenvolve como uma espiral catalisando os fenômenos do mundo e os contextos sócio-históricos do narrador e do leitor para se transformar em obra. São fios constantemente tecidos, produzindo sentido sempre em uma relação dialógica, como também diria Bakhtin (2010). Resende (2009) ressalta então que "nesse lugar, contrária à noção de um discurso formatado que explica o mundo, trabalha-se com a ideia da construção de uma narrativa que está em processo".

\section{Fronteira}

Nossa reflexão perpassa então pela ideia de que as palavras, as narrativas, embora estejam em um processo contínuo, podem servir também de blocos que constituem os muros nas fronteiras. Ressignificá-las e produzir outros sentidos são abrir fendas ou mesmo derrubar esses muros. Por isso, o processo narrativo está sempre aberto. Então, é a partir das narrativas nas fronteiras, espaços de onde se emanam 

para refletir sobre textos jornalísticos que se forjaram na esteira de eventos que foram chamados de "crise dos refugiados". Ao estar na fronteira, os que buscam refúgio a tem como uma ponte para atravessar as suas vicissitudes ao mesmo tempo em que está ali a possibilidade do encontro com o "outro" em toda a sua estranheza. Nesse espaço há negociações e conflitos que, de alguma forma, são atravessados também por outros agentes, como os meios de comunicação.

Pensamos que é também nos espaços de fronteiras que estas disputas ganham um real valor simbólico quando narradas. Elas se materializam na vontade dos corpos em se deslocar e ocupar outros territórios. Há nesse ponto uma relação entre narrativa e alteridade, pois o impedimento ao deslocamento e a barreira erguida são ações moldadas por construções sobre o "outro", que é identificado a partir de uma narrativa anterior. Nas fronteiras, as alteridades se veem ao mesmo tempo em que negociam o próprio espaço de conflito, pois se ela é concebida, ela está lá também para separar, repelir, afeita a desamparar o outro.

Stuart Hall (2013, p. 36), ao pensar a diáspora, diz que seu conceito está tacitamente atrelado ao de fronteira, diferença e às configurações da identidade cultural ${ }^{11}$. Para Hall, há dois caminhos que simbolizam uma diáspora: um que é fechado e "se apoia sobre uma concepção binária de diferença. Está fundado sobre a construção de uma fronteira de exclusão e depende da construção de um 'Outro' e de uma oposição rígida entre o dentro e o fora". Nesse aspecto que as políticas de segregação são desenvolvidas, onde é necessário manter uma cisão irrestrita entre o eu e o outro. Por outro lado, ao pensar as diásporas emaranhadas nas configurações de identidade cultural a partir da experiência caribenha, Hall salienta que elas requerem:

a noção derridiana de différance ${ }^{12}$ - uma diferença que não funciona através de binarismos, fronteiras veladas que não separam finalmente, mas são também places de passage, e significados que são posicionais e relacionais, sempre em deslize ao longo de um espectro sem começo nem fim (HALL, 2013, p. 36).

11 Para Hall (2013), as identidades culturais não podem ser tomadas como reproduções de tradições imutáveis, mas como uma produção constante, de uma tradição enquanto em "mutação". 12 Ver DERRIDA, Jacque. Margens da filosofia. Campinas: Papirus, 1991, p.45. 
Assim, há ao menos essas duas maneiras de experimentar as fronteiras. Ao ser passagem, ou podemos dizer também porosa, ela é o "entre-lugares" apontados por Homi Bhabha (1998, p. 20), que "fornecem o terreno para a elaboração de estratégias de subjetivação - singular ou coletiva - que dão início a novos signos de identidade e postos inovadores de colaboração e contestação, no ato de definir a própria ideia de sociedade". Como pontua Mezzadra (2017, p. 34), a fronteira é por definição um espaço aberto em expansão, uma frente móvel em um processo de formação contínua. Nesse entendimento, as fronteiras nacionais em sua fixidez não são capazes de enclausurar as culturas, especialmente em suas diásporas. No entanto, leva-se em conta que o processo de emaranhamento entre os vários atores não se dá de forma equânime, mas "são inscritos diferentemente pelas relações de poder" (HALL, 2013, p. 38).

As identidades vão funcionar então como gatilho para essas disputas, pois são forjadas no choque, na friç̧ão, na linguagem. Nesse processo de construção de identidades, as práticas discursivas são preponderantes para demarcar as diferenças, para estabelecer o eu e o outro, para "o fechamento e a marcação de fronteiras simbólicas, a produção de efeitos de fronteiras" em que a identificação é "um processo de articulação, uma suturação, uma sobredeterminação, e não uma subsunção. Há sempre 'demasiado' ou 'muito pouco' - uma sobredeterminação ou uma falta, mas nunca um ajuste completo, uma totalidade" (HALL, 2014, p. 105).

\section{Narrando um dos lados das fronteiras}

Consideremos então alguns títulos de matérias publicadas pela Folha de São Paulo em 2015 que conotavam contenção, controle e fronteira (Tabela 2). A partir dos títulos podemos tomar algumas inferências sobre como a leitura dos acontecimentos é evidenciada nas notícias e como a territorialidade está presente na narrativa.

Tabela 2 - Títulos de matérias publicadas pela Folha de São Paulo em 2015 sobre a "crise dos refugiados" e espaços de controle que tiveram assinaturas de jornalistas brasileiros

\begin{tabular}{|l|l|}
\hline Data & Título \\
\hline $20 / 04$ & Europa anuncia medidas para conter fluxo de imigrantes \\
\hline $31 / 07$ & Imigrantes vagam por Calais à espera de chance para entrar na Inglaterra \\
\hline $30 / 08$ & Tratados como 'animais', sírios descrevem travessia pela Europa \\
\hline
\end{tabular}




\begin{tabular}{|l|l|}
\hline $02 / 09$ & Crise de refugiados põe em xeque o espaço único europeu \\
\hline $04 / 09$ & Áustria autoriza migrantes a passarem por seu território para ir à Alemanha \\
\hline $05 / 09$ & Chegada de refugiados desata caos na fronteira entre a Hungria e a Áustria \\
\hline $14 / 09$ & Plano de cotas trava, e Europa cria barreiras à entrada de refugiados \\
\hline
\end{tabular}

Há uma produção de sentido que relaciona migrantes ou refugiados à desordem ao impor palavras de ordem tais como "conter", criar "barreiras" e reforçar "segurança". Outras como pôr "em xeque" e desatar "caos" nos educam a olhar disciplinarmente (Gomes, 2004, 2018) para estes sujeitos que se deslocam como seres que desordenam e são não-pertencentes àqueles espaços. Dos sete títulos listados, dois não trazem explicitamente uma perspectiva de que o migrante ou refugiado é o causador da desordem ou que mereçam alguma repulsa, mas indica quem o controla: "Imigrantes vagam por Calais à espera de chance para entrar na Inglaterra" e "Áustria autoriza migrantes a passarem por seu território para ir à Alemanha". Aqui se tem a conotação da fronteira como ponte, passagem, em direção a um território imaginado. No entanto, um dia depois, o título de outro texto sobre o deslocamento forçado na fronteira da Áustria desfaz qualquer possibilidade de atravessamento: "Chegada de refugiados desata caos na fronteira entre a Hungria e a Áustria".

Observemos este texto produzido e publicado pela Folha de São Paulo em 2 de setembro de 2015 - "Crise de refugiados põe em xeque o espaço único europeu".13 Seguem alguns trechos:

O drama dos refugiados na Europa ganhou novas cenas de desespero nesta terça (1ํ), desta vez com milhares na Hungria impedidos de seguir viagem de trem para países como Alemanha e Áustria.

Ao mesmo tempo, cresce o debate sobre a fragilidade do trânsito livre pela área em que não há controle imigratório nas fronteiras, o chamado espaço Schengen.

13 Disponível em: https://www1.folha.uol.com.br/mundo/2015/09/1676642-crise-de-refugiados-doleste-poe-em-xeque-o-espaco-unico-europeu.shtml. 
Implementada há 20 anos, a área reúne hoje 26 países europeus que díspensam o uso de passaporte entre eles. $O$ modelo permite, na prática, que refugiados e imigrantes cruzem de um país para o outro sem monitoramento.

Temos um espaço de trânsito livre para os membros dos 26 países que fazem parte do acordo do espaço Schengen. Neste espaço há uma territorialidade assentada em sua concretude, no poder que emana dos que o controlam, ao mesmo tempo que é um espaço de disputa e tensões. Permitir o trânsito dos migrantes e refugiados seria também pôr em xeque essa territorialidade e o poder de controlar seus corpos, como deduz o texto. Permitir que possam transitar livremente como os europeus simbolicamente seria conceder sua liberdade de mobilidade ao "outro", sujeito migrante ou refugiado, categorizado como não-pertencente àquele lugar. Há aqui uma reverberação da política de controle dos corpos que se dissemina pela narrativa da notícia em que se incuta o perigo que as brechas fronteiriças podem acarretar para a Europa. Ao reverberar estas narrativas, a territorialidade deixa de ser apenas geográfica, física, confinada no espaço Schengen, e ganha um valor simbólico.

Há também uma manutenção do contexto geográfico através de divisão do mundo em representações dicotômicas, europeus/migrantes ou europeus/refugiados. Não se sabe quem são esses sujeitos a não ser pela sua categorização de migrante ou refugiado. Desta forma, a narrativa se envereda para estabelecer as identidades como se estas fossem fixas e rígidas (identidades coletivas), tão em vigor do século 19 até a primeira metade do século 20 (WOLTON, 2004), e sem possibilidades de imbricações e transformações. Joga-se um véu sobre as intersubjetividades. Esta produção de sentido que ecoa com as narrativas jornalísticas se territorializa e se cristaliza, alastrando ideias, saberes e poderes.

Mais do que pensar como são postos os títulos e estes fragmentos de notícias, direcionamos nosso olhar para entender que o que sabemos do mundo através desses relatos é atravessado pela narrativa europeia, que tem suas vozes ampliadas no Brasil através da narrativa de imprensa. Nesse ponto, percebemos uma das perspectivas da territorialidade narrativa, que é a expansão de um poder para além fronteiras, muito mais próxima da ideia de territorialidade apontada por Haesbaert e Sack. 


\section{Atravessando a fronteira}

Dos sete títulos mencionados, um nos traz a situação de vulnerabilidade daqueles que arriscam suas vidas nessas jornadas, e merece uma maior atenção: "Tratados como 'animais', sírios descrevem travessia pela Europa."14 Aqui, há um atravessamento da fronteira também pelo jornalismo em direção aos que buscam refúgio, quando se apresenta um olhar em direção ao influxo. Há o relato do périplo de um grupo de 10 sírios que fogem da guerra através da Turquia, chegam à Grécia, passam três dias com mais 6 mil refugiados na fronteira com a Macedônia por esta estar bloqueada, depois seguem para Belgrado, Sérvia. De lá, o objetivo é chegar à Hungria.

O sírio Ali Khalifah, 42, é a pessoa que narra a travessia do grupo para o repórter. É quem condiciona a si todo o drama que os demais têm vivido.

Encontramos a fronteira fechada e muitas pessoas apanharam da polícia. Ficamos assustados com o barulho e as bombas de gás lacrimogêneo lançadas sobre nós. Nestes dias eu chorei temendo pelo futuro das minhas filhas

O repórter, então, completa, assumindo a voz de Khalifah:

No momento em que a fronteira foi reaberta, todos correram mato adentro, com medo de serem barrados novamente.

A narrativa nos aponta para uma tessitura em que os sujeitos, repórter e as pessoas em busca de refúgio se embrenham, dividem e constroem a história em uma relação dialógica e polifônica no sentido bakhtiniano (2010), pois a história pertence as duas consciências. O texto tem o relato do repórter como uma testemunha que faz parte da cena. Voltemos ao início da matéria, por exemplo:

O relógio marcava $19 h 35$ quando o engenheiro eletricista sírio Ali Khalifah, 42, e parte da família chegavam ao terminal de ônibus em Belgrado, capital da Sérvia. As centenas de pessoas que chegam a todo momento não estão em férias ou viajando a trabalho, mas

14 Disponível em: https://www1.folha.uol.com.br/mundo/2015/08/1675502-tratados-como-animaissirios-descrevem-travessia-pela-europa.shtml. 
sim no meio de uma arriscada travessia rumo à União Europeia, fugindo dos conflitos no Oriente Médio.

A praça ao lado do terminal virou um acampamento improvisado. Poucos contam com barracas de náilon para poder se esconder das tempestades de verão nos Bálcãs.

Tem-se aqui as subjetivações que se dão na fronteira, como aponta Mezzadra (2017). É nela que repórter e refugiado se relacionam e possibilitam a construção de uma outra narrativa, agora em uma perspectiva em que o debate se dá a partir de outros referenciais, dos próprios deslocados na fronteira. Há agora uma inserção de um jornalismo mais próximo dos sujeitos outrora colonizados. Ao contrário de textos que se pressupõe uma narrativa a partir da Europa em direção aos refugiados, com vozes de figuras públicas e organizações circunscritas àquele território, somos apresentados agora a quem está do outro lado da fronteira. A matéria segue para seu final com a voz de Khalifah:

Não somos animais nem terroristas. Só queremos viver em paz na Europa ou até mesmo voltar um dia à Síria. Olhem por nós.

Ao passo que a territorialidade narrativa, na perspectiva de Resende, circunscreve ações e processos que se assemelham e dialogam entre si para além das fronteiras, possibilitando outras ordens e tessituras, o que se aproxima desta última análise, também é possível deparar-se com outra ideia de territorialidade narrativa a partir do conceito de territorialidade em Haesbaert, que se expande de forma homogênea e hegemônica e que neutraliza em certa medida outros modos de narrar o mundo, como pontuamos em relação aos outros títulos.

Sem tentar impor uma dicotomia de narrativas, chamamos a atenção na verdade para a reverberação de um debate que está sendo feito a partir de um referencial, o europeu, o que implica em um alastramento de pontos de vistas sobre a questão do deslocamento forçado diante das fronteiras em que as vulnerabilidades dos que buscam refúgio são postas em segundo plano. O alastramento de um modo de enxergar o mundo a partir dos mesmos referenciais nos conduz a ter uma narrativa dominante onde a preocupação está em debater como a Europa vai lidar com os processos de migração 
forçada e menos em debater a situação de vulnerabilidade dos que buscam refúgio diante das fronteiras, como foi narrado neste último exemplo.

\section{Algumas considerações}

O jornalismo exerce-se como um guia que nos põe em contato com o mundo, no entanto sob o seu filtro e suas produções de significados possíveis, pois é uma prática social discursiva e ideológica por natureza. Desta forma, devemos considerar o jornalismo, através do fluxo de informação, como um importante modulador e ator nos processos de disputa.

Ao tratarmos do jornalismo e da narrativa como dispositivos da territorialidade, pretendeu-se desdobrá-los através de um dos recortes possíveis da territorialidade narrativa, que a nosso ver pode-se estabelecer com o alastramento de uma determinada visão dentro de uma rede de informação que catalisa múltiplos territórios e que, nesse caso, se expande das fronteiras europeias para outros espaços. Por outro lado também pontuamos que o jornalismo é constantemente suscetível a reconfigurações onde novos pensamentos podem ser estabelecidos, como algo sempre mutável, onde é possível também produzir outros tipos de territorialidades narrativas.

Neste trabalho, percebemos que a crise dos refugiados em 2015 desvelou tanto os sistemas de controle fronteiriço europeu quanto o apagamento pela imprensa de outros territórios, como do continente africano, que são atravessados pelos deslocamentos forçados. Há nesse sentido uma territorialidade que mapeia e cartografa quais rotas dessa crise estarão nas narrativas jornalísticas. Contudo, queremos ressaltar que a insistência em se deslocar, não apenas para fugir das vicissitudes da vida, é, sobretudo, abrir caminhos e produzir outras narrativas, é também territorializar-se.

\section{Referências}

ACNUR. Agência da ONU para Refugiados. https://www.acnur.org

ALBUQUERQUE JR., Durval Muniz de. A invenção do Nordeste e outras artes. São Paulo: Cortez, 1999.

ANDERSON, Benedict. Comunidades Imaginadas. São Paulo: Companhia das Letras, 2008.

BAKHTIN, Mikhail. Problemas da Poética de Dostoievski. Rio de Janeiro: Forense Universitária, 2010. 
BHABHA, Homi K. O local da cultura. Belo Horizonte: Editora UFMG, 1998.

COLON, Leandro. Plano de cotas trava, e Europa cria barreiras à entrada de refugiados. Folha de São Paulo, 14 Set. 2015.

https://www1.folha.uol.com.br/mundo/2015/09/1681752-plano-de-cotas-trava-e-europa-

cria-barreiras-a-entrada-de-refugiados.shtml

Leandro. Chegada de refugiados desata caos na fronteira entre a Hungria e

a Áustria. Folha de São Paulo, 5 Set. 2015.

https://www1.folha.uol.com.br/mundo/2015/09/1678319-chegada-de-refugiados-cria-caosna-fronteira-entre-a-hungria-e-a-austria.shtml

Leandro. Áustria autoriza migrantes a passarem por seu território para ir à Alemanha. Folha de São Paulo, 4 Set. 2015.

https://www1.folha.uol.com.br/mundo/2015/09/1678173-austria-autoriza-migrantes-apassarem-por-seu-territorio-para-ir-a-alemanha.shtml

, Leandro. Crise de refugiados põe em xeque o espaço único europeu. Folha de São Paulo, 2 Set. 2015.

https://www1.folha.uol.com.br/mundo/2015/09/1676642-crise-de-refugiados-do-leste-poe-

em-xeque-o-espaco-unico-europeu.shtml

Leandro. Imigrantes vagam por Calais à espera de chance para entrar na Inglaterra. Folha de São Paulo, 31 Jul. 2015.

https://www1.folha.uol.com.br/mundo/2015/07/1662713-cameron-diz-que-deportara-

enxame-vindo-do-eurotunel.shtml

, Leandro. Europa anuncia medidas para conter fluxo de imigrantes. Folha de São Paulo, 20 Abr. 2015.

https://www1.folha.uol.com.br/mundo/2015/04/1619067-europa-anuncia-medidas-para-

conter-fluxo-de-imigrantes.shtml

CHARAUDEAU, Patrick. Discursos da Mídia. São Paulo: Contexto. 2012.

GEORGIUS, Myria; Zaborowski, Rafael. Media coverage of the "refugee crisis": a cross-European perspective. Council of Europe Report, 2017.

Global Trends Forced Displacement 2018. UNHCR, 2019.

https://www.unhcr.org/statistics/unhcrstats/5d08d7ee7/unhcr-global-trends-2018.html

Global Trends Forced Displacement 2015. UNHCR, 2016.

https://www.unhcr.org/statistics/unhcrstats/576408cd7/unhcr-global-trends-2015.html 
Global Trends Forced Displacemente 2012. UNHCR, 2013.

https://www.unhcr.org/statistics/country/5399a14f9/unhcr-global-trends-

2013.html?query=global\%20trends

GOMES, Mayra. Rodrigues. Bordando o manto do mundo: prática jornalística, Volume 1. São Paulo: ECA-USP, 2018.

Mayra Rodrigues. Jornalismo e filosofia da comunicação. São Paulo: Escrituras Editora, 2004.

HAESBAERT, Rogério. Dilemas de conceitos: Espaço-território e Contenção territorial. In: SAQUET, Marcos Aurélio; SPOSITO, Eliseu Savério (Org.). Territórios e territorialidades: Teorias, processos e conflitos. São Paulo: Editora Expressão Popular, 2009, p. 95-120.

Rogério. Dos múltiplos territórios à multiterritorialidade. Porto Alegre, 2004. Disponível em: https://www.ufrgs.br/petgea/Artigo/rh.pdf

HALL, Stuart. Quem precisa de identidade? In: Tomaz Tadeu da Silva (Org.) Identidade e diferença: A perspectiva dos Estudos Culturais. Petrópolis, RJ: Editora Vozes, 2014.

Stuart. Pensando a diáspora: reflexões sobre a terra no exterior. In: SOVIK, Liv (Org.). Da diáspora: Identidades e mediações culturais. Tradução Adelaine La Guardia Resende... (et al.). - 2. ed - Belo Horizonte: Editora UFMG, 2013. p. 27-55.

MEZZADRA, Sandro; NEILSON, Brett. La frontera como metodo. Traficantes de suenos,: Madrid, 2017.

MOTTA, Luiz Gonzaga. Análise crítica da narrativa. Brasília: Editora Universidade de Brasília, 2013.

RESENDE, F. "Geographies of the South: unfolding experiences and narrative territorialities". In: AMANSHAUSER, H; BRADLEY, K. (eds.). Navigating the Planetary. Vienna: Verlag für moderne Kunst, 2020.

, Fernando; IQANI, Mehita. Theorizing media in and across the global south:

narrative as territory, culture as flow. In: REZENDE, Fernando; IQANI, Mehita (Org.).

Media and the Global South. Londres: Routledge, 2019.

, Fernando. O jornalismo e suas narrativas: as brechas do discurso e a possibilidade do encontro. Revista Galáxia, São Paulo, n. 18, p.31-43, dez. 2009.

RICOEUR, Paul. Tempo e Narrativa (tomo 1). Campinas, SP: Papirus, 1994.

RODRIGUES, Talyson. Tratados como 'animais', sírios descrevem travessia pela Europa. Folha de São Paulo, 30 Ago. 2015. 


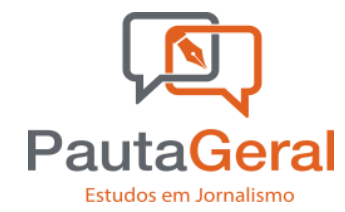

https://www1.folha.uol.com.br/mundo/2015/08/1675502-tratados-como-animais-siriosdescrevem-travessia-pela-europa.shtml

SACK, Robert D. Human Territoriality: A Theory. Annals of the Association of American Geographers, Vol. 73, No. 1. p. 55-74, mar. 1983.

WOLTON, Dominique. Pensar a comunicação. Brasília: Editora UNB, 2004.

ZAMIN, Angela. Jornalismo e território: a cartografia diária das coisas do mundo. Revista Fronteiras - estudos midiáticos. 1Vol. 15, No. 2. p. 96-107 mai./ago. 2013. 